\title{
Trochlear and Abducens Nerve Neurinomas Accompanied by a Cerebellopontine Angle Meningioma
}

\author{
-Case Report-
}

\author{
Takaaki BePPU, Yuki YoshIDA, Tsukasa WADA, Hiroshi ARAI, \\ Michiyasu SUzUKI, Kiyoshi KURODA, and Akira OGAWA
}

Department of Neurosurgery, Iwate Medical University, Morioka

\begin{abstract}
A 66-year-old male presented with cerebellovestibular symptoms and hypesthesia of the V2 area of his face. Neuroimaging only detected a cerebellopontine angle (CPA) meningioma. The CPA meningioma was removed using the lateral suboccipital approach, which exposed small neurinomas arising from the trochlear and abducens nerves. Both neurinomas were removed intracapsularly. Postoperatively hypesthesia resolved, but other symptoms were unchanged. A karyotypic analysis of chromosome 22 and estrogen receptor analysis suggested absence of neurofibromatosis II, but the cause(s) of the genesis of multiple diverse tumors was not determined. This extremely rare combination of neurinomas and meningioma was probably incidental, as there are no reports of any case with a combination of the trochlear and the abducens nerve neurinomas, much less one accompanied by a meningioma.
\end{abstract}

Key words: trochlear nerve, abducens nerve, neurinoma, meningioma,

diverse multiple brain tumors

\section{Introduction}

Intracranial neurinomas generally arise from the vestibular nerve or less commonly from the trigeminal nerve, whereas other nerves, particularly the oculomotor nerves, i.e., the oculomotor, trochlear, and abducens nerves, are very rare sites. ${ }^{0,12)}$ There has been no case reported combining two neurinomas arising from oculomotor nerves, much less one accompanied by a meningioma. It is common knowledge that multiple diverse primary brain tumors are frequently caused by neurofibromatosis II (NF-2). ${ }^{3,23)}$ Such associations are extremely rare in the absence of NF$2 .{ }^{17,27)}$ We describe a case of multiple trochlear and abducens nerve neurinomas associated with a cerebellopontine angle (CPA) meningioma but without NF-2.

\section{Case Report}

A 66-year-old male presented with a 5-year history of tinnitus, right hearing disturbance, and vertigo. Four months prior to admission, he had diplopia due

Received August 28, 1996; Accepted January 9, 1997 to inability to abduct the right eye. One month prior to admission, the right hearing disturbance developed into deafness. Physical examination revealed sustained horizontal nystagmus of the right lateral gaze and dysmetria of the right side, suggesting right cerebellovestibular symptoms. Hypesthesia in the V2 area of the left side of the face was found. His past history and familial history included no episode suggesting irradiation or NF-2.

$\mathbf{T}_{1}$-weighted magnetic resonance imaging with gadolinium demonstrated a homogeneous enhanced mass with a smooth angle in the right CPA, but no finding suggesting other tumors (Fig. 1). Six-vessel angiography showed poor visualization of the feeding vessel to the tumor but without mass effect. The diagnosis was right CPA meningioma.

Three weeks after admission, the meningioma was resected through the lateral suboccipital approach in the prone position. After the craniectomy, retraction of the cerebellum exposed a tumor mass arising from the tentorium, occupying the CPA space and compressing the facial and vestibulocochlear nerves backward. This CPA tumor was resected sharply using a microsurgical technique. Although the trigeminal nerve was compressed forward by this tumor, 


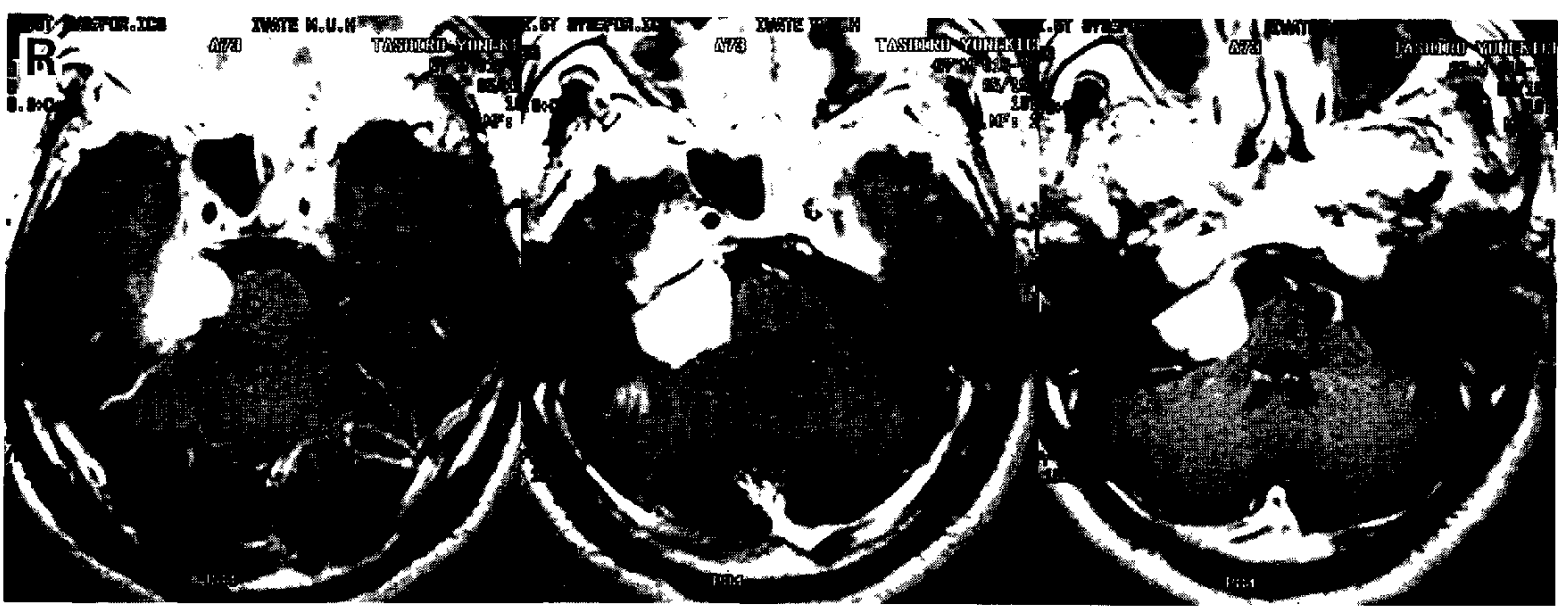

Fig. $1 T_{1}$-weighted magnetic resonance images with gadolinium showing a homogeneous enhanced mass suggesting a meningioma in the right cerebellopontine angle, but no other lesions.

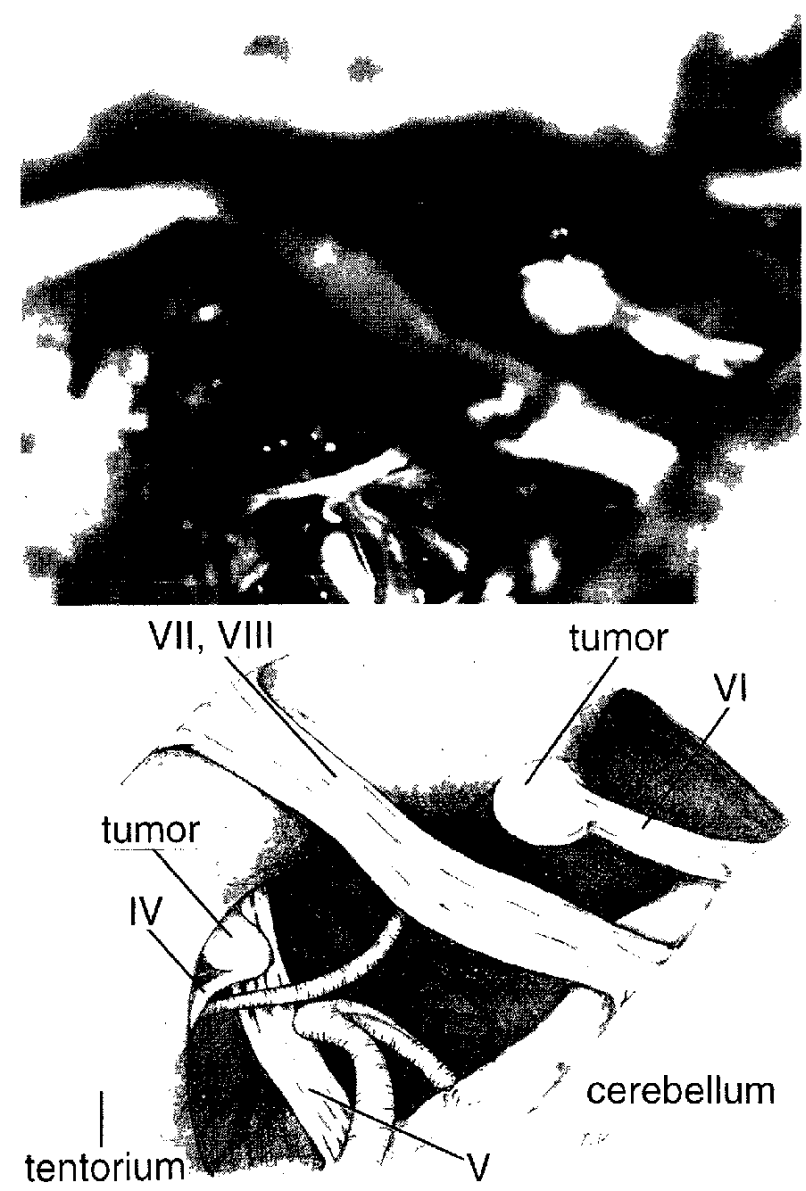

Fig. 2 Photograph (upper) and scheme (lower) showing the surgical field after removal of the tentorial meningioma, and two small tumors arising from the trochlear and abducens nerves. the trochlear and abducens nerves were intact. After complete removal of the CPA tumor, yellow-colored tumors were found arising from the trochlear and abducens nerves (Fig. 2). The tumors arising from the trochlear and abducens nerves were $2 \times 2 \times 1 \mathrm{~mm}$ and $3 \times 3 \times 3 \mathrm{~mm}$, respectively. These tumors were thought to be neurinomas, and were removed intracapsularly by parallel incision of the nerves.

Postoperatively, the abduction disturbance of the right eye was unchanged, although the hypesthesia of his face disappeared. Trochlear nerve palsy was not present. The histological diagnosis of the CPA tumor was fibroblastic meningioma with typical features (Fig. 3A). The tumors arising from the trochlear and abducens nerves presented similar features with "perivascular whorl-like structures," which were thick and hyalinized vessels surrounded by club-shaped nuclei (Fig. 3B, C). This finding suggested that the tumors were schwannomas. Ultimately, the diagnosis was eventually established as schwannoma because S-100 protein was detected but endothelial membrane antigen was not in both tumors (Fig. 4). Since NF-2 is recognized as a cause of meningioma and neurinoma, chromosome 22 was examined by G-banded karyotypic analysis using lymphocytes from the patient's peripheral blood at Nihon Gene Research Laboratories, Inc. (Sendai). This analytical method showed that chromosome 22 was normal.

We tried to detect the estrogen-receptor protein in each tumor by an immunohistochemical procedure. Briefly, after blocking with normal serum, paraffinembedded sections were treated with anti-estrogen receptor protein mouse monoclonal antibody diluted 1:100 with phosphate buffered saline (Novocas- 


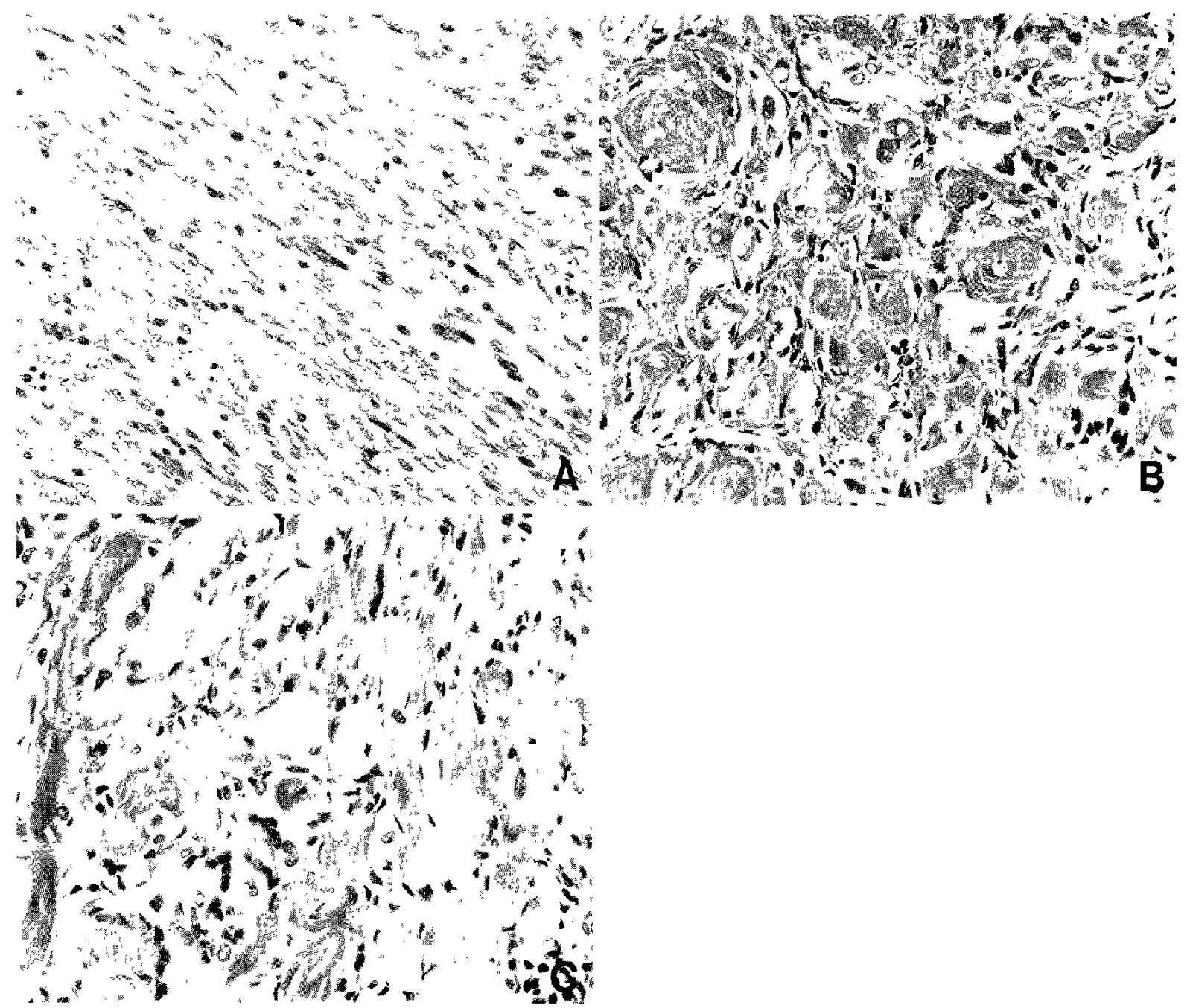

Fig. 3 Photomicrographs showing the features characteristic of fibroblastic meningioma (A), and "perivascular whorl-like structures" of tumors arising from the trochlear nerve (B) and the abducens nerve (C). HE stain, $\times 100$.

tra, Newcastle, U.K.), and then stained using the avidine-biotin-peroxidase complex method. The estrogen-receptor protein could not be detected in any tumor tissues (not shown).

\section{Discussion}

Trochlear nerve neurinoma or abducens nerve neurinoma have been found in only 15 $\operatorname{cases}^{1,2,5,6,9,12,16,18,20,24,26,29)}$ and five cases, ${ }^{4,7,10,11,18)}$ respectively. However, there has been no report about a case with both neurinomas.

Symptoms unrelated to tumor origin, for example abducens nerve palsy due to a trigeminal nerve neurinoma, often appear with or without the expected symptoms of neurinoma. ${ }^{15,30)}$ This rule seems to also apply to trochlear nerve neurinoma. Except for trochlear nerve palsy, the characteristic symptom of trochlear nerve neurinoma is unusual sensory sensations in the face on the contralateral side. ${ }^{26)}$ The cause may be that neurinoma involves only part of the nerve fibers, without affecting the root of the original nerve, and the tumor compresses the brainstem. ${ }^{2,13)}$ The occurrence of trochlear nerve palsy was $7 / 13(54 \%)$ and unusual facial sensations was $6 /$ $13(46 \%)$ in previously reported cases of trochlear nerve neurinoma. ${ }^{1)}$ In our case, no symptoms related to trochlear nerve neurinoma including unusual facial sensations on the contralateral side occurred. A possible explanation might be that the trochlear nerve neurinoma was too small to compress the other cranial nerves or the brainstem. We speculate that the hypesthesia of the face ipsilateral to the tumors resulted from compression of the trigeminal 


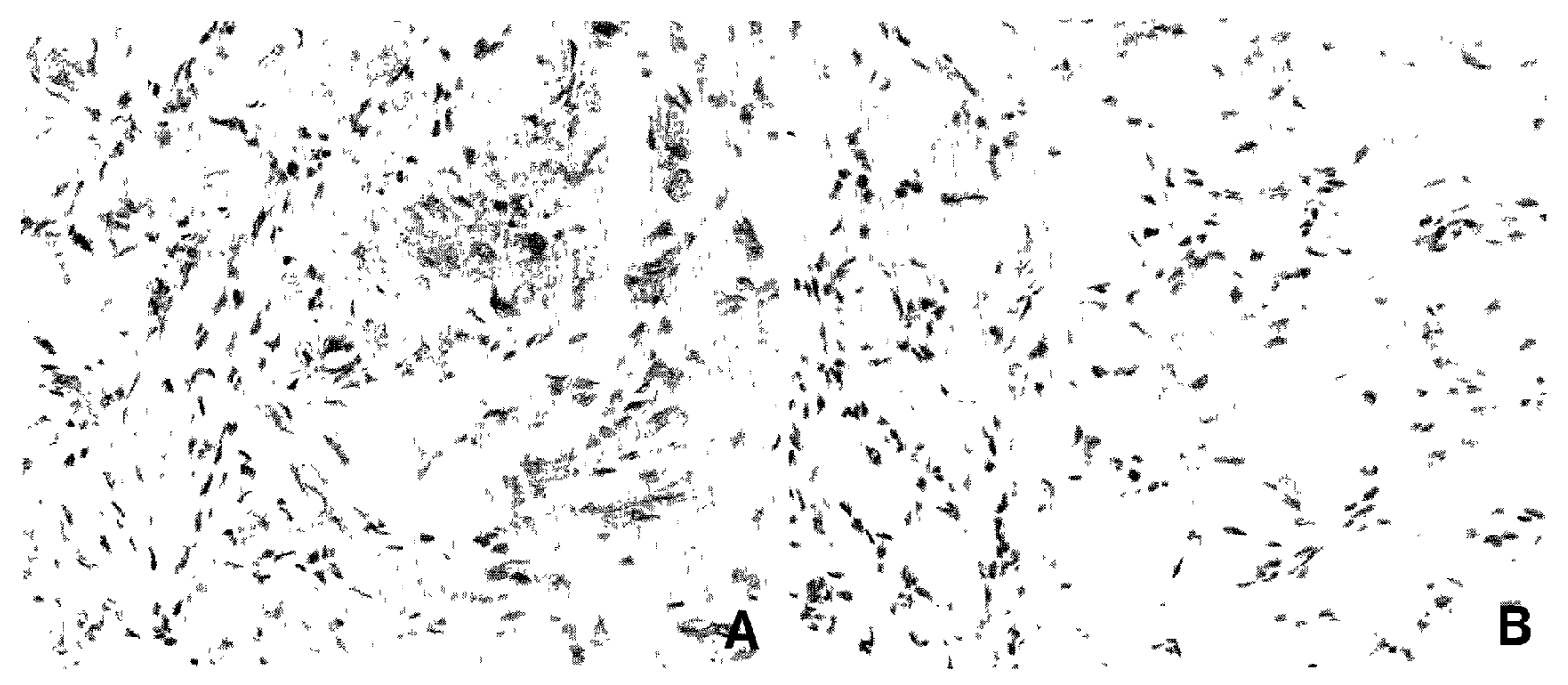

Fig. 4 Photomicrographs showing immunohistochemical detection of the S-100 protein (A) and the endothelial membrane antigen (B). $\times 100$.

nerve by the CPA meningioma. All five previous cases of the abducens nerve neurinoma had abducens nerve palsy, and remained symptom-less for a long period when compared with other neurinomas. $^{7}$ This phenomenon may be related to the anatomical relationship of the tumor site to bone. ${ }^{7}$ Briefly, the tumor would require a long period before compression to bone, because the abducens nerve neurinoma grew in the ambient cistern away from bone, whereas other cranial neurinomas are always close to the bony structure. In our case, the period before onset of abductive disturbance would be short relative to the tumor size, probably because the abducens nerve neurinoma was situated near the portal of the clival dura (Fig. 2), unlike the previous case.

Surgery for trochlear nerve neurinomas has almost always used the subtemporal-transtentorial approach. ${ }^{1,2,6,29)}$ Treatment of two cases of abducens nerve neurinoma used the suboccipital approach ${ }^{7}$ and the subtemporal approach. ${ }^{18)}$ The lateral suboccipital approach provided an adequate microscopic surgical field for removing the CPA meningioma and both neurinomas in our case (Fig. 2). The trochlear nerve neurinoma is commonly situated just beneath the tentorial edge, partly adhering to the tentorium. ${ }^{1,2,6,29]}$ Our operative findings were similar. Aggressive resection of the trochlear nerve or abducens nerve neurinomas, which arise from pure motor nerves, can cause nerve palsy. ${ }^{21,22]}$ Postoperatively, our patient did not display any new symptom of ocular movement, because the resection of the neurinomas was only partial.
Our patient had a multiple diverse brain tumors which consisted of the trochlear nerve neurinoma, the abducens nerve neurinoma, and a CPA meningioma. It is generally known that NF-2 frequently causes intracranial neurinoma and meningioma. The NF-2 may be caused by inactivation of the merlin tumor suppressor encoded in chromosome band $22 q 12{ }^{19]}$ Our patient had no past or familial history of neurofibromatosis, and a G-banded karyotypic analysis disclosed that the chromosome 22 was normal. These results suggested that our patient's tumors were not caused by NF-2. A case combining neurinoma and meningioma but not accompanied by NF-2 is very rare. Arai et al. ${ }^{3)}$ have summarized 126 cases of intracranial and intraspinal multiple diverse tumors described previously in the literature. They identified 42 cases as combined cases of neurinoma and meningioma; 33 of which were accompanied by NF-2. Therefore, almost all cases of combined neurinoma and meningioma are caused by NF-2. Six patients, one male and five females, with combined intracranial neurinoma and meningioma without NF-2 presented with neurinomas arising from the vestibulocochlear nerve in four cases, and the facial nerve and accessory nerve neurinoma in one each. ${ }^{27}$ Our case is extremely rare, since the patient was male and had both trochlear nerve and abducens nerve neurinomas accompanied by meningioma.

The relationship between brain tumors and sex hormones has been investigated intensively. ${ }^{25)}$ The estrogen receptor, one of the sex hormonal receptors, is frequently detected in both neurinoma and 
meningioma. ${ }^{8,14)}$ Changes of estrogen concentration in pregnancy affects the proliferation activity of meningioma. ${ }^{8)}$ In neurinomas, the estrogen receptor is more detectable in females, and the expression of the estrogen receptor is closely related to cellularity and the production of collagen fibers. ${ }^{14)}$ Therefore, the estrogen receptor may be involved in the generation and proliferation of both neurinomas and meningiomas. However, we could not detect any estrogen receptor in our patient's neurinomas and meningioma.

Embryologically, meningocytes and Schwann cells are derived from cells of the neural crest. ${ }^{28)}$ This theory would suggest that simultaneous occurrences of neurinoma and meningioma should be common. However, combinations of these tumors without NF2 are very rare. The incidence of each tumor making up the combination might be a factor, because combinations of tumors derived from different origins, e.g., glioma and meningioma, appear more often than those from the same origin. ${ }^{17)}$

Finally, we suggest that the combination of neurinomas and meningioma occurred incidentally in our case because no causative mechanism can be identified based on present knowledge. Much more research to investigate the cause(s) of multiple diverse brain tumors is anticipated.

\section{Acknowledgment}

We thank T. Sugai, M.D. (Dept. of Clinical Pathology) and A. Kurose, M.D. (1st Dept. of Pathology) for their comments and suggestions, and to Ms. Virginia L. Braymer for help in preparation of this manuscript. We are also grateful to J. Anbo for his immunohistochemical work.

\section{References}

1) Abe $T$, Iwata $T$, Shimazu $M$, Iida $M$, Izumiyama $H$, Matsumoto K, Mizutani T, Tanaka N, Aruga T: [Two cases of trochlear nerve neurinoma]. No Shinkei Geka 22: 371-375, 1994 (Jpn, with Eng abstract)

2) Abe T, Iwata T, Shimazu M, Matsumoto K: Trochlear nerve neurinoma associated with a giant thrombosed dissecting aneurysm of the contralateral vertebral artery. Surg Neurol 42: 438-441, 1994

3) Arai H, Chichibu M, Ikuta F, Oyake Y: [Triple diverse multiple primary tumors in the nervous system: Report of an autopsy case with special reference to their origins]. No To Shinkei 21: 1241-1249, 1969 (Jpn)

4) Barat JL, Marchal JC, Bracard S: Neurinoma of the oculomotor nerves. Apropos of 2 cases. Neurochirurgie 38: 182-187, 1992

5) Boggan JE, Rosenblum ML, Wilson CB: Neurilemmo- ma of the fourth cranial nerve. Case report. J Neurosurg 50: 519-521, 1979

6) Celli P, Ferrante L, Acqui M, Mastronardi L, Fortuna A, Palma L: Neurinoma of the third, fourth, and sixth cranial nerves: A survey and report of a new fourth nerve case. Surg Neurol 38: 216-224, 1992

7) Chen BH: Neurinoma of the abducens nerve. Neurosurgery 9: 64-66, 1981

8) Donnell MS, Meyer GA, Gonegan WL: Estrogenreceptor protein in intracranial meningiomas. I Neurosurg 50: 499-502, 1979

9) Garen PD, Harper CG, Teo C, Johnston IH: Cystic schwannoma of the trochlear nerve mimicking a brain-stem tumor. Case report. J Neurosurg 67: 928930,1987

10) Ginsberg F, Peyster RG, Rose WS, Drapkin AJ: Sixth nerve schwannoma: MR and CT demonstration. J Comput Assist Tomogr 12: 482-484, 1988

11) Hansman ML, Hoover ED, Peyster RG: Sixth nerve neurinoma in the cavernous sinus: CT features. Case report. J Comput Assist Tomogr 10: 1030-1032, 1986

12) Ho KL: Schwannoma of the trochlear nerve. Case report. J Neurosurg 55: 132-135, 1981

13) Jefferson $G$ : The trigeminal neurinomas with some remarks on malignant invasion of the Gasserian ganglion. Clin Neurosurg 1: 11-54, 1955

14) Kasantikul V, Brown WJ: Estrogen receptors in acoustic neurilemmomas. Surg Neurol 15: 105-109, 1981

15) Katoh K, Kadoya S, Emori T, Kwak R: [Trigeminal neurinoma presenting abducens nerve palsy as initial symptoms: A report of two cases]. No Shinkei Geka 13: 555-560, 1985 (Jpn, with Eng abstract)

16) King JS: Trochlear nerve sheath tumor. Case report. J Neurosurg 44: 245-247, 1976

17) Kitamura K, Nakamura N, Terao H, Hayakawa I, Kamano S, Ishijima T, Sano K: [Primary multiple brain tumors]. No To Shinkei 17: 109-117, 1965 (Jpn)

18) Leunda G, Vaquero J, Cabezudo J, Garcia-Uria J, Bravo G: Schwannoma of the oculomotor nerves. Report of four cases. J Neurosurg 57: 563-565, 1982

19) MacCollin M, Mohney T, Trofatter J, Werteiecki W, Ramesh V, Gusella J: DNA diagnosis of neurofibromatosis 2: Altered coding sequence of the marlin tumor suppressor in an extended pedigree. JAMA 270: 2316-2320, 1993

20) Maurice-Williams RS: Isolated schwannoma of the fourth cranial nerve: Case report. J Neurol Neurosurg Psychiatry 52: 1442-1443, 1989

21) Nathan H, Goldhammer $Y$ : The rootlets of the trochlear nerve; anatomical observations in human brains. Acta Anat (Basel) 84: 590-596, 1973

22) Nathan H, Ouaknine G, Kosary JZ: The abducens nerve: Anatomical variations in its course. $J$ Neurosurg 41: 561-566, 1974

23) Nitta T, Sato K: [A clinical study of 21 patients with neurofibromatosis I and II]. No Shinkei Geka 23: 131135, 1995 (Jpn, with Eng abstract)

24) Samii M: Intracranial compression of the third, fourth, sixth cranial nerves by tumors, in Samii $M$, Jannetta PJ (eds): Cranial Nerves: Anatomy, Patholo- 
gy, Pathophysiology, Diagnosis, Treatment. Berlin, Springer-Verlag, 1981, pp 241-248

25) Schnegg JF, Tribolet ND: Neurinoma of the facial nerve associated with a parietal meningioma. Surg Neurol 21: 19-22, 1984

26) Tokuriki Y, Yamashita J, Kikuchi H, Asato R, Handa $\mathrm{H}$ : Trochlear nerve neurinoma. Case report. Neurol Med Chir (Tokyo) 28: 70-73, 1988

27) Tsukamoto H, Hikita T, Takaki T: Cerebellopontine angle meningioma associated with cranial accessory nerve neurinoma. Case report. Neurol Med Chir (Tokyo) 34: 225-229, 1994

28) Weston TA: The migration and differentiation of neural crest cells, in Abercrombie M, Brachet J, King TJ (eds): Advances in Morphogenesis. New York, Academic, 1970, pp 41-114

29) Yamamoto $M$, Jimbo $M$, Ide $M$, Kubo O: Trochlear neurinoma. Surg Neurol 28: 287-290, 1987

30) Yamashita T, Asato R, Handa H, Nakao S, Ogata M: Abducens nerve palsy as initial symptom of trigeminal schwannoma. I Neurol Neurosurg Psychiatry 40: 1190-1197, 1977

Address reprint requests to: T. Beppu, M.D., Department of Neurosurgery, Iwate Medical University, 19-1 Uchimaru, Morioka 020, Japan. 